\title{
Livros
}

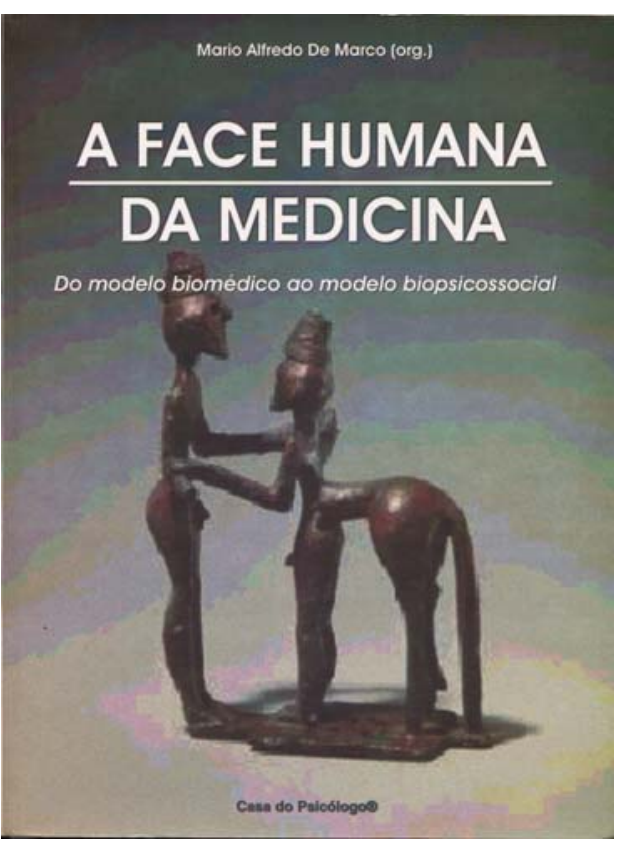

Livro

\section{A face humana da medicina: do modelo biomédico ao modelo biopsicos- social}

Mario Alfredo De Marco (org). São Paulo: Casa do Psicólogo, 2003, 269 páginas. ISBN 85-7396-271-2.

Atualmente, estamos observando uma crescente insatisfação com os atendimentos e um progressivo aumento dos processos contra médicos. De acordo com as entidades de classe, essas querelas ocorrem devido a problemas de relacionamento entre médicos e pacientes. Esta relação tem sido cada vez mais dificultada pela presença de um intermediário, no caso da medicina de grupo, e pelo tipo de sociedade em que vivemos, na qual mais valem as aparências, a velocidade e o lucro, do que o cuidado às pessoas. Além disso, observamos que o avanço tecnológico na medicina e 0 culto às especializações, embora tenham aumentado os recursos diagnósticos e terapêuticos, contribuíram para criar a ilusão de que seria possível "curar doentes" sem o contato mais próximo com a pessoa que adoece. É nesta atmosfera de insatisfação, e conseqüente busca de soluções para esses problemas, que surge o livro "A face humana da medicina: do modelo biomédico ao modelo biopsicossocial".

Trata-se de uma obra, fruto de uma Ionga jornada do autor - que é professor de psicologia médica da Universidade Federal de São Paulo e interconsultor - e de sua vivência sobre a dificuldade que é formar profissionais que não deixem de ter em mente a face humana e artística da medicina. Nesta árdua tarefa de escrever sobre o tema, De Marco conta com a colaboração de vários profissionais experientes na área, que redigiram diversos capítulos do livro. 0 texto se estrutura em quatro partes: Parte I - Aspectos históricos; Parte II - A reintegração do psicossocial ao modelo biomédico; Parte III - A prática; e Parte IV - Experiência no complexo EPM-UNIFESP-HSP.

Na parte I, o autor faz uma primorosa revisão histórica para demonstrar como e em que contexto chegamos ao modelo biomédico. Além disso, critica o "especialismo", enquanto uma perversão das especializações, cujo problema não seria a fragmentação do doente e sim, a perda da visão binocular pelo médico. Assim, os profissionais não conseguiriam mudar sua visão da parte para o todo e vice-versa, de acordo com a necessidade. 0 sufixo "ismo" é utilizado pelo fato daespecialização se aproximar mais de um dogma do que da ciência. 0 médico usaria sua teoria, então, como "o leito de procusto", no qual, se a vítima seqüestrada que ia ser amarrada (aqui o paciente) fosse menor, esta era esticada e, se fosse maior, seus pés eram cortados.

Na parte II, são delimitados os campos que foram criados na tentativa de reintegrar o psicossocial ao modelo biomédico: medicina psicossomática, interconsulta, psicologia da saúde e psicologia médica. Como contribuições da medicina psicossomática são destacados: o trabalho desenvolvido por Balint, o conceito de alexitimia (sem palavras para os sentimentos) e o estudo de mecanismos de enfrentamento ("coping"). A interconsulta é vista como sendo importante por se ocupar de "cuidar de quem cuida" e pela sua função integradora, pois o interconsultor tem uma postura complementar e tem o cuidado de não "Iotear" o paciente, como mais um especialista. Nas partes de psicologia da saúde e psicologia médica, o autor nos alerta sobre os riscos do profissional "psi" ser utilizado no contexto médico para acentuar a divisão entre mente e corpo, caso aceite ser "o responsável" pelos aspectos psicológicos, enquanto o médico assistente acredita poder, então, se ocupar somente do corpo do paciente. Além disso, é discutida a delimitação de competências.

Na parte III, são analisados os fatores que dificultam e os que propiciam uma prática mais humanizada. São discutidos, dentre outros: a formação de profissionais, a intermediação do trabalho médico, a atenção à saúde dos profissionais, o trabalho realizado por outros profissionais da saúde e a identificação e atenção às situações críticas. Um fio condutor desta parte seria a noção de que 0 ensino médico e o modelo de gestão institucional - que não reconhecem e não refletem sobre o homem que há no médico contribuem para um sentimento de desamparo no aluno/profissional, que passa, então, a agir de forma estereotipada, cínica e fria, para tentar evitar entrar em contato com os próprios sentimentos de impotência, fracasso e hostilidade. Algumas questões levantadas nesta parte do livro já foram abordadas em outras obras brasileiras como a de Perestrello, ${ }^{1}$ Botega $^{2}$ e Cataldi et al. ${ }^{3}$ Entretanto, acreditamos que o grande mérito do livro tenha sido, sobretudo, o fato de este se focar em uma única pergunta: como contribuir para resgatar a face humana da medicina? Na parte IV, é descrita a experiência dos serviços no complexo da 
Escola Paulista de Medicina e do Hospital São Paulo. Eis aqui quase que um manual dando "0 caminho das pedras" para aqueles que lecionam psicologia médica, praticam interconsulta ou querem montar um serviço de atenção à saúde de alunos e residentes. Neste aspecto, assemelha-se ao livro de Millan et al., ${ }^{4}$ que também, de forma muito generosa, descreve os serviços e a prática realizados na Faculdade de Medicina da Universidade de São Paulo.

Merece discussão a ideologia, expressa pelo autor do capítulo sobre experiências em supervisão, de que a atividade de interconsulta possa ser realizada de forma "pontual" (sem acompanhar 0 paciente e a equipe até a alta). A maioria dos interconsultores entende sua atividade como um processo, no qual é fundamental que a equipe de saúde se sinta assistida durante toda a internação do paciente.

Por ter sido escrito por diversos autores, senti um pouco a falta de unidade e continuidade entre alguns capítulos do livro. Talvez isso se deva ao profundo respeito do autor pela individualidade e experiência de cada colaborador, mas sugiro que este aspecto seja lembrado nas próximas edições deste livro, que certamente surgirão.

Para concluir, agradecemos a generosidade do autor e de seus colaboradores por dividirem conosco suas experiências nesta bela obra. Sugiro sua leitura a todos interessados no tema mas, sobretudo, para os profissionais "angustiados" com o estado atual da prática médica e preocupados em buscar formas de meIhorá-la.

\section{Referências}

1.Perestrello D. A Medicina da Pessoa. $4^{a}$ ed. Rio de Janeiro: Atheneu; 1996.

2.Botega NJ, editor. Prática psiquiátrica no hospital geral: interconsulta e emergência. Porto Alegre: Artmed; 2002.

3.Neto AC, Gauer GJC, Furtado NR, editores. Psiquiatria para estudantes de medicina. Porto Alegre: Edipucrs; 2003.

4. Millan LR, De Marco OLN, Rossi E, Arruda PCV. 0 universo psicológico do futuro médico. São Paulo: Casa do Psicólogo; 1999.

\section{Letícia Maria Furlanetto}

Departamento de Clínica Médica da Universidade Federal de Santa Catarina e Departamento de Interconsulta da ABP.

\section{Livro \\ Saúde Mental da Mulher}

Táki Athanássios Cordás e Fábio Tapia Salzano

A saúde mental da mulher, desde há muito, desperta o interesse dos estudiosos do assunto, principalmente em função dos diferenciais psicobiológicos que marcam os transtornos mentais da muIher nas diferentes etapas de sua vida, incluindo controvérsias e particularidades inerentes à mesma. Em "Saúde Mental da Mulher" - editado pelos professores Táki Athanássios Cordás e Fábio Tapia Salzano, do Instituto de Psiquiatria do Hospital das Clínicas da FMUSP, e com a participação de um seleto grupo de colaboradores -, os autores desenvolveram um primoroso trabaIho na composição dos 12 capítulos dessa obra, que vai da abordagem de uma possível psicologia específica da mulher em sua relação com o mundo, até uma visão abrangente da sexualidade

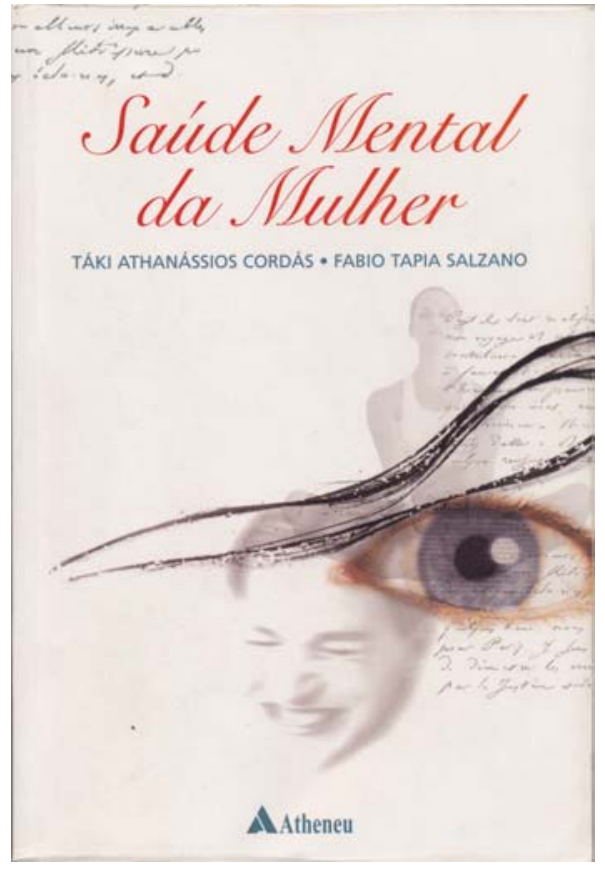

da mesma sem, entretanto, perder a integralidade do "ser muIher". Nos capítulos intermediários, são discutidos os transtornos mentais nos períodos pré-menstrual, climatério e menopausa, incluindo os períodos especiais da gestação e puerpério. Seguemse capítulos estimulantes, onde são abordadas características inerentes e diferenças eventuais entre sexos quanto à psicofarmacologia e às farmacodependências. Os demais capítulos avaliam os transtornos do humor, de ansiedade, esquizofrenia, transtornos de personalidade e os alimentares. As avaliações vão além, englobando aspectos etiopatogênicos e fisiopatológicos, considerando as dificuldades e controvérsias na discussão dos distúrbios.

"Saúde Mental da Mulher" é de leitura envolvente, pela atualidade do tema, e obrigatória, pelos aspectos inéditos e de grande abrangência, além da importante contribuição à psiquiatria brasileira. Interessa de perto não só a especialistas das diversas áreas da Saúde Mental, mas também a uma gama de profissionais incluindo sexólogos, ginecologistas, clínicos e pós-graduandos.

Talvez, numa próxima edição, que entendemos virá em breve, fosse interessante incluir comentários sobre o período prépúbere, considerando que, por exemplo, transtornos alimentares poderiam eventualmente ter início nessa fase.

\section{Veruska Lastoria Amigo}

Programa de Orientação e Assistência aos Transtornos Alimentares (PROATA) da EPM-UNIFESP e Centro de Atenção Integrada à Saúde Mental (CAISM) da Irmandade da Santa Casa de Misericórdia de São Paulo. 